\title{
Successful surgical treatment of extrahepatic biliary papillomatosis diagnosed with endoscopic retrograde cholangiopancreatography: a case report
}

\author{
Tarik Adioui ${ }^{* *}$, Hassan Seddik' ${ }^{1}$ Hicham Baba², Badr Slioui ${ }^{3}$, Abdelmounaim Ait Ali², Fatima Zohra El Hamdi', \\ Ahmed Benkirane ${ }^{1}$ and Aziz Zentar ${ }^{2}$
}

\begin{abstract}
Introduction: Biliary papillomatosis is a condition characterized by multiple papillary tumors of variable distribution and extent within the biliary tract. Papillary carcinoma can develop in these lesions. It is a rare biliary pathological entity and its clinical features and outcome are not well known.

Case presentation: We experienced a case of biliary papillomatosis in a 51-year-old North African man who presented with obstructive jaundice. Laboratory tests showed elevated bilirubin, alkaline phosphatase and gamma-glutamyl transpeptidase levels. Imaging (ultrasound and magnetic resonance imaging) was suggestive of Klatskin tumor associated to common bile duct stones. After endoscopic retrograde cholangiopancreatography, a balloon sweep retrieved friable tissue from his bile ducts. Histology demonstrated papillary adenomatous proliferation showing high-grade dysplasia and he was referred for surgical management.

Conclusions: Although biliary papillomatosis is rare, it is a premalignant condition that should be well known and considered in all diagnoses of obstructive jaundice. We report a new case of biliary papillomatosis and highlight the contribution of endoscopic retrograde cholangiopancreatography in the diagnosis of this condition.
\end{abstract}

Keywords: Biliary papillomatosis, Biliary tract, Obstructive jaundice

\section{Introduction}

Biliary papillomatosis (BP) is a rare condition of unknown etiology characterized by multiple papillary tumors within the intrahepatic and/or extrahepatic biliary tree that can cause biliary obstruction [1]. It is a low-grade neoplasm with high malignant potential and should be regarded as a premalignant lesion. BP commonly affects adults in their sixth to seventh decade of life and is twice as common in males as females $[1,2]$. It presents with recurrent episodes of abdominal colic, jaundice, acute cholangitis and the presence of biliary stones and/or infection. We describe a case of $\mathrm{BP}$ in which endoscopic retrograde cholangiopancreatography (ERCP) played an important role in the diagnosis of this condition.

\footnotetext{
* Correspondence: tarikadioui@gmail.com

'Department of Gastroenterology II, Mohamed V Teaching Military Hospital, Rabat 10100, Morocco

Full list of author information is available at the end of the article
}

\section{Case presentation}

A 51-year-old North African man presented with a 1 -month history of fluctuating jaundice with pale stools and dark urine, right upper quadrant pain, and intermittent vomiting. His past medical history included neurosyphilis for approximately 8 years. A physical examination revealed little upper abdominal quadrant tenderness. Biochemistry demonstrated elevated bilirubin, alkaline phosphatase and $\gamma$-glutamyl transpeptidase levels, and leukocytosis. Ultrasound and magnetic resonance imaging showed a complete stop at the biliary bifurcation compatible with a Klatskin tumor associated to common bile duct stones (Figure 1). Endoscopic retrograde cholangiography revealed dilated intrahepatic ducts and common bile duct above multiple polylobed filling defects. These 


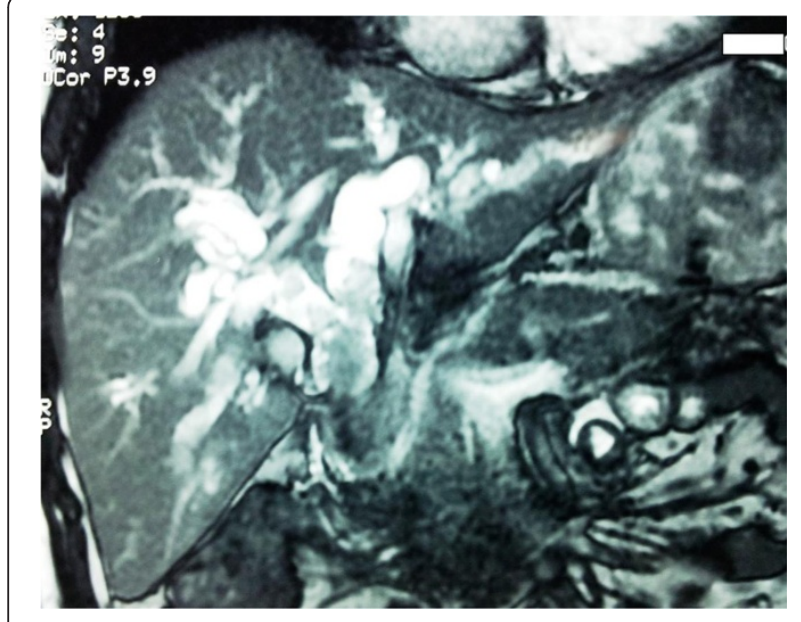

Figure 1 Magnetic resonance image showing a complete stop at the biliary bifurcation compatible with a Klatskin tumor associated to common bile duct stones.

findings were mainly suggestive of multiple impacted stones of his common bile duct, cholangiocarcinoma, or hemobilia. After an endoscopic sphincterotomy, a balloon sweep retrieved friable, polypoid soft tissue from his bile ducts (Figure 2). Two biliary plastic stents were placed. Histology of the tissue demonstrated papillary adenomatous proliferation showing high-grade dysplasia; the patient was referred for surgical management. Laparoscopic exploration demonstrated a dilated common biliary duct. A transversal choledochotomy revealed a papillary polylobed mass (Figures 3 and 4). Common bile duct resection was performed with macroscopically safe margins and biliary reconstruction was achieved by Roux-en-Y hepaticojejunostomy.

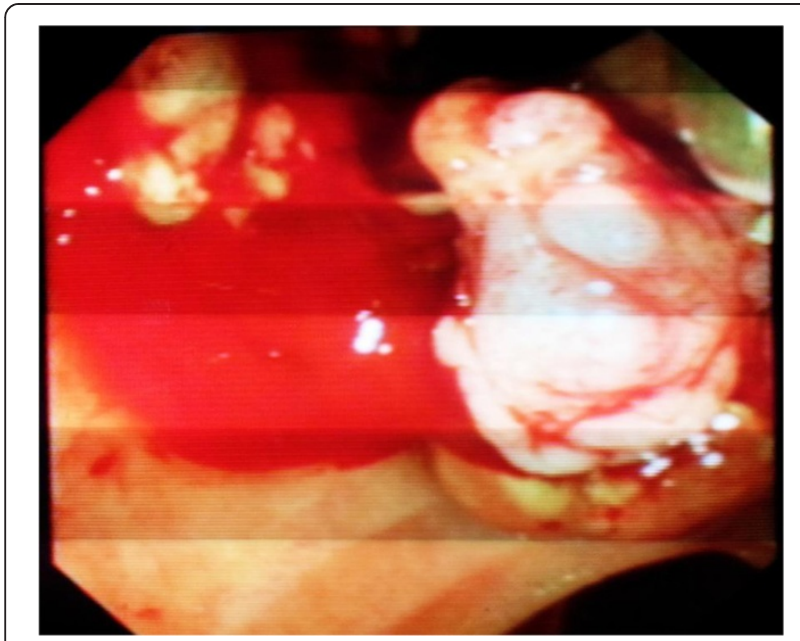

Figure 2 After endoscopic retrograde cholangiopancreatography, balloon sweep retrieved friable, polypoid soft tissue from bile ducts.

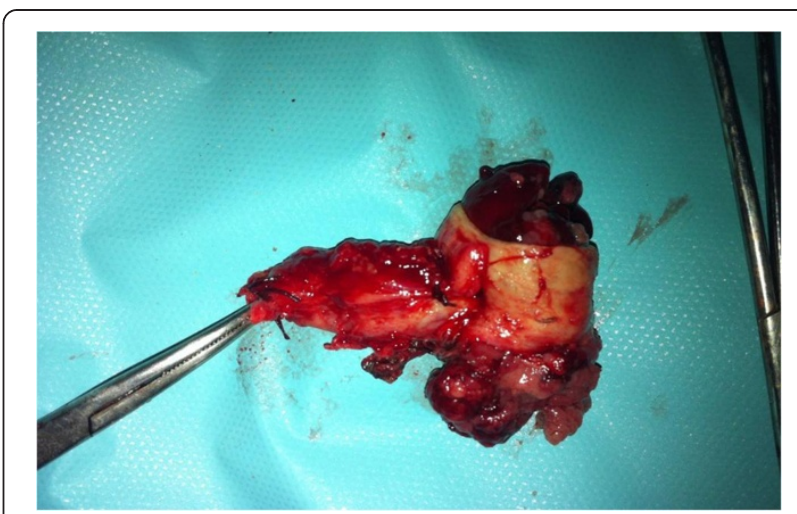

Figure 3 Post operative view of common bile duct containing papillary material.

\section{Discussion}

BP is papillary adenomatosis within the biliary tree. It is a very rare disorder that typically presents with fluctuant obstructive jaundice.

BP can be thought of as a collection of benign papillary adenomas within which adenocarcinoma can develop and spread along the bile duct mucosa [1-3]. Recent literature suggests BP has a rate of malignant transformation between $41 \%$, and $83 \%[1,2]$.

Since the first case described by Chappet in 1894, almost 100 cases have been reported.

$\mathrm{BP}$ pathogenesis is unclear and appears related to irritation and inflammation of the biliary tree. The roles of bile stasis and recurrent infections are also underlined [4]. Some associations were described: chronic stone irritation, clonorchis infestation, reactive hyperplasia in Caroli's disease, ectopic pancreatic tissue, anomalous biliary tree and primitive sclerosing cholangitis [5]. Our patient had neurosyphilis and, to the best of knowledge, this is the first report of this association.

Clinical features are obstructive jaundice and recurrent cholangitic episodes. These features are due to partial or

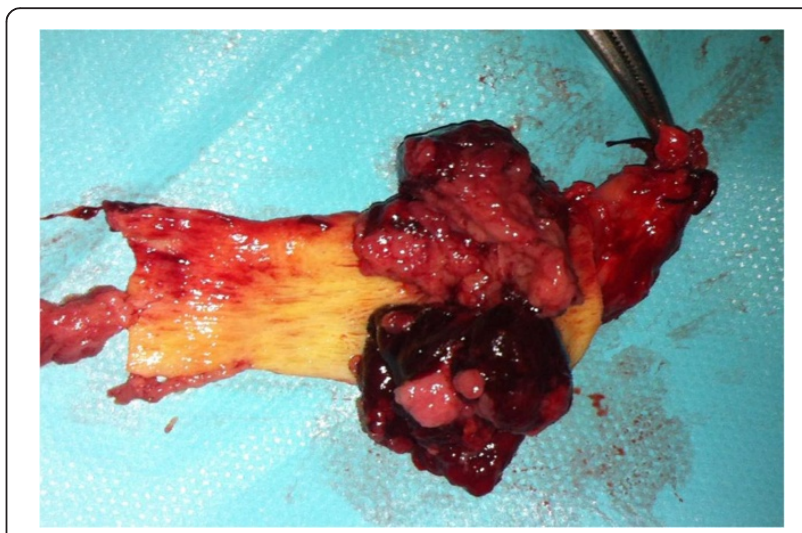

Figure 4 Surgical specimen showing polylobed papillary mass within the common bile duct. 
intermittent obstruction of the bile duct secondary to mucus production, tumor enlargement or tumor fragments $[6,7]$.

The most common imaging finding is intrahepatic ducts and/or common bile duct dilatation (polypoid filling defects, mural irregularities) [8]. Other features such as the presence of multiple intraductal masses within the lumen or attached to the wall of bile ducts are typically visualized on magnetic resonance cholangiopancreatography [2-6]. Computed tomography scan may reveal soft tissue densities in the dilated bile ducts or thickened and enhanced bile duct walls [1]. During ERCP, typical characteristics include: amorphous filling defects, irregularity of the bile duct wall, reduced motility on irrigation and mucus discharge from the papilla. BP may then be classified as either mucin-hypersecreting $\mathrm{BP}$ or non-mucin-producing BP depending on the presence or absence of mucobilia. These morphological features are mainly suggestive of hilar cholangiocarcinoma, and we aim here to draw readers' attention to consider BP in all diagnosis of hilar tumors, which avoids condemning patients with palliative therapy systematically. During a contrast cholangiogram, it is important to obtain opacification of the entire biliary tract to determine precisely the ductal extension of the disease, which helps to guide the treatment plan, including surgery $[9,10]$.

Curative treatment can be achieved through surgical resection in localized disease [2-11]. However, local resection is characterized by a high rate of recurrence due to either positive resection margins or recurrence due to the multifocality of the disease. In the case of diffuse or recurrent BP, resection of the biliary tree by liver transplantation and pancreaticoduodenectomy can be curative $[1,2,12,13]$.

Endoscopic therapy through ERCP was initially used for palliation in patients who were poor surgical candidates. Argon plasma coagulation has been attempted for the treatment of premalignant mucosal diseases of the digestive tract, due to its low depth and satisfactory local effects, and its use in the biliary tree has been scarcely described [14]. Palliative procedures also include percutaneous management with drainage and stenting, and intraluminal brachytherapy with iridium-192. Untreated $\mathrm{BP}$ that does not undergo malignant transformation eventually leads to chronic cholestasis due to mechanical obstruction resulting in septic cholangitis and hepatic failure [2].

\section{Conclusions}

$\mathrm{BP}$ is a rare condition characterized by multiple papillary adenomas involving the biliary tract which leads to recurrent cholangitis. It is considered a rare benign disease with a high malignancy potential and tendency to spread superficially. Definitive treatment is by means of radical surgical resection and/or liver transplantation.

\section{Consent}

Written informed consent was obtained from the patient for publication of this case report and accompanying images. A copy of the written consent is available for review by the Editor-in-Chief of this journal.

\section{Abbreviations}

BP: Biliary papillomatosis; ERCP: Endoscopic retrograde cholangiopancreatography.

\section{Competing interests}

The authors declare that they have no competing interests.

\section{Authors' contributions}

AT and SH evaluated the patient and were major contributors in writing the manuscript. SB analyzed MRI data. SH and FZE realized the ERCP. BH, AA, and ZA performed the surgical management. BA and ZA reviewed the manuscript. All authors read and approved the final manuscript.

\section{Author details}

'Department of Gastroenterology II, Mohamed V Teaching Military Hospital, Rabat 10100, Morocco. ${ }^{2}$ Department of General Surgery I, Mohamed V Teaching Military Hospital, Rabat 10100, Morocco. ${ }^{3}$ Department of Radiology, Mohamed V Teaching Military Hospital, Rabat 10100, Morocco.

Received: 8 December 2013 Accepted: 13 February 2014

Published: 13 May 2014

\section{References}

1. Lee SS, Kim M-H, Lee SK, Jang SJ, Song M-H, Kim K-P, Kim HJ, Seo D-W, Song DE, Yu E, Lee S-G, Min YI: Clinicopathologic review of 58 patients with biliary papillomatosis. Cancer 2004, 100:783-793.

2. Vassiliou I, Kairi-Vassilatou E, Marinis A, Theodosopoulos T, Arkadopoulos N, Smyrniotis V: Malignant potential of intrahepatic biliary papillomatosis: a case report and review of the literature. World J Surg Oncol 2006, 4:71.

3. Kim HJ, Kim MH, Lee SK, Yoo KS, Park ET, Lim BC, Park HJ, Myung SJ, Seo DW, Min Yl: Mucin-hypersecreting bile duct tumour characterized by a striking homology with an intraductal papillary mucinous tumor (IPMT) of the pancreas. Endosc 2000, 32:389-393.

4. Nakanuma Y, Sasaki M, Ishikawa A, Tsui W, Chen T-C, Huang S-F: Biliary papillary neoplasm of the liver. Histol Histopathol 2002, 17:851-861

5. Kim KH, Kim CD, Lee HS, Lee SJ, Jeen YT, Chun HJ, Song CW, Lee SW, Um SH, Choi JH, Ryu HS, Hyun JH: Biliary papillary hyperplasia with clonorchiasis resembling cholangiocarcinoma. Am J Gastroenterol 1999, 94(2):514-517.

6. Ma KF, Lu PP, Chau LF, Chong AK, Lam HS: Clinical and radiological features of biliary papillomatosis. Australas Radiol 2000, 44(2):169-173.

7. Imvrios G, Papanikolaou V, Lalountas M, Patsiaoura K, Giakoustidis D, Fouzas I, Anagnostara E, Antoniadis N, Takoudas D: Papillomatosis of intra- and extrahepatic biliary tree: successful treatment with liver transplantation. Liver Transp/ 2007, 13(7):1045-1048.

8. Hoang TV, Bluemake DA: Biliary papillomatosis: CT and MR findings. J Comput Assist Tomogr 1998, 22:671-672.

9. Kim YS, Myung SJ, Kim SY, Kim HJ, Kim JS, Park ET, Lim BC, Seo DW, Lee SK, Kim MH, Min Yl: Biliary papillomatosis: clinical, cholangiographic and cholangioscopic findings. Endosc 1998, 30:763-767.

10. Barnett JL, Knol J: Use of a novel "adoptable" baby cholangioscope to diagnose a biliary papillary adenoma. Gastrointest Endosc 1995, 41:70-72.

11. Cox H, Ma M, Bridges R, Debru E, Bath O, Sutherland F, Dixon E: Well differentiated intrahepatic cholangiocarcinoma in the setting of biliary papillomatosis: a case report and review of the literature. Can J Gastroenterol 2005, 19(12):731-733. 
12. Dumortier J, Scoazec JY, Valette PJ, Ponchon T, Boillot O: Successful liver transplantation for diffuse biliary papillomatosis. J Hepatol 2001, 35(4):542-543.

13. Vibert $E$, Dokmak S, Belghiti J: Surgical strategy of biliary papillomatosis in Western countries. J Hepatobiliary Pancreat Sci 2010, 17:241-245.

14. Christiaens P, Decock S, Buchel O, Bulté K, Moons V, D'Haens G, Van Olmen G: Endoscopic trimming of metallic stents with the use of argon plasma. Gastrointest Endosc 2008, 67:369-371.

doi:10.1186/1752-1947-8-148

Cite this article as: Adioui et al: Successful surgical treatment of extrahepatic biliary papillomatosis diagnosed with endoscopic retrograde cholangiopancreatography: a case report. Journal of Medical Case Reports 2014 8:148.

\section{Submit your next manuscript to BioMed Central and take full advantage of:}

- Convenient online submission

- Thorough peer review

- No space constraints or color figure charges

- Immediate publication on acceptance

- Inclusion in PubMed, CAS, Scopus and Google Scholar

- Research which is freely available for redistribution 